Diagnosis and management of endocrine related tumors. Edited by R.J. SANTEN \& A. MANNI. Martinus Nijhoff, xiv $+456 \mathrm{pp}, 1984, £ 48.95$. ISBN 0898386365 .

This is a useful book, which attempts to cover a spectrum of major topics in adult Clinical Endocrinology. The initial chapter dealing with neuroanatomic and neurosurgical aspects of pituitary endocrine disease, is a practical and historically informative introduction for endocrinologists, whose enthusiasm falls short of attendance at neurosurgical operations.

In subsequent chapters - Arafah et al. review their substantial experience of pituitary microsurgery for Acromegaly and Prolactinomas. They make a good case for the use of additional tests besides basal growth hormone estimations in defining an 'endocrine-cure' in Acromegaly and attempt to give direction to the management of Prolactinomas, which however, will continue to remain controversial until more follow-up data are available. The treatment of thyroid carcinoma with radio-iodine is dealt with rather didactically by $\mathrm{Dr}$ Beierwaltes, although no one could question his enormous experience. Surgery for thyroid carcinoma is discussed in a balanced fashion by Timothy Harrison, whilst Hamburger et al. make a justifiable plea for greater use of the thyroid needle biopsy by all physicians and surgeons managing thyroid disease. Surgical management of hyperparathyroidism is dealt with very well by Kaplan \& Fredland, with a pragmatic approach to preoperative localization of tumour. The diagnosis and management of Insulinomas is outlined very comprehensively and in considerable depth by the authors (Fajans \& Vinik) who probably have one of the largest personal experience of such cases.

The later chapters discuss Glucagonomas, Somatostatinomas, Gastrinomas, Vipomas, PPomas and the syndrome of multiple endocrine adenomatosis type 1, which are all topics that are attracting increasing interest in endocrine circles. Though the book seems overpriced at around $£ 50$

\section{Other Books Received}

Molecular Medicine - Vol. 1. Ed: A.D.B. Malcolm. IRL Press - (1984). $£ 13.50$ (viii + 208) pages. ISBN 0904147932.

Radiation and Skin. By: C.S. Potten. Taylor and Francis - (1985). (xi + 225) pages. ISBN 085066 2575.

Hematopoietic Stem Cells - Hematology - Vol. 2. Eds: D.W. Golde and F. Takaku. Marcel Dekker (1985). \$83.00. (xii + 379) pages. ISBN 0824772245. for an individual purchase, it should be a useful addition to the endocrine library.

S. Rafeeq Ahmed

Gynecologic cancer. Edited by A.A. ForASTIERE. Contemporary Issues in Clinical Oncology, Vol. 2. Churchill Livingstone, $x i+307$ pp., $£ 32.00$. ISBN 0 $44308274 \mathrm{X}$.

We are in the middle of an epidemic of publishing about Clinical Oncology. Each year new review journals appear to update our knowledge and latterly these have been supplemented by a large number of hardback editions or series. This book is the second edition of a 'Contemporary Issues in Clinical Oncology' series, and purports to deal with cancers of the female genital tract. In fact the volume is not comprehensive, barely touching upon, for example, nonepithelial cell ovarian carcinomas. Surgeons, radiotherapists, oncologists and epidemiologists have written separately about their different areas, as a result of which the book lacks cohesion. I found the book patchy, and would suggest that the over reliance on ASCO abstracts as references in some of the chapters is a dangerous precedent. I also found much of the text uncritical, with recommendations for new treatment often based on inadequate or preliminary data. Certainly many of the treatment proposals would be at odds with clinical practice in the UK. Set against this a number of the chapters provide excellent overviews of specific areas, e.g. investigational techniques in ovarian cancer by Ozols and colleagues.

Is the book worth buying? At this price the answer for the individual is likely to be no. I think many of the review journals, more effectively manage to review the 'state of the art' in a given area, and question the usefulness of a text such as this to a specialist reader.

G. M. Mead

Nutrition and Cancer. By: R.J. Shamberger. Plenum - (1984). \$49.50. (xiii + 372) pages. ISBN 0 306415334 .

Pharmacokinetics of Anticancer Agents in Humans. Eds: M.M. Ames, G. Powis and J.S. Kovach. Elsevier - (1983). \$113.50. (xviii + 476) pages. ISBN 0444804184. 